\section{Augmentative releases of green lacewings suppressed variegated grape leafhopper in experimental plots and commercial vineyards; however, effectiveness varied greatly. Field studies show that improved release methods and a better understanding of lacewing biology are needed to optimize commerclal release programs.}

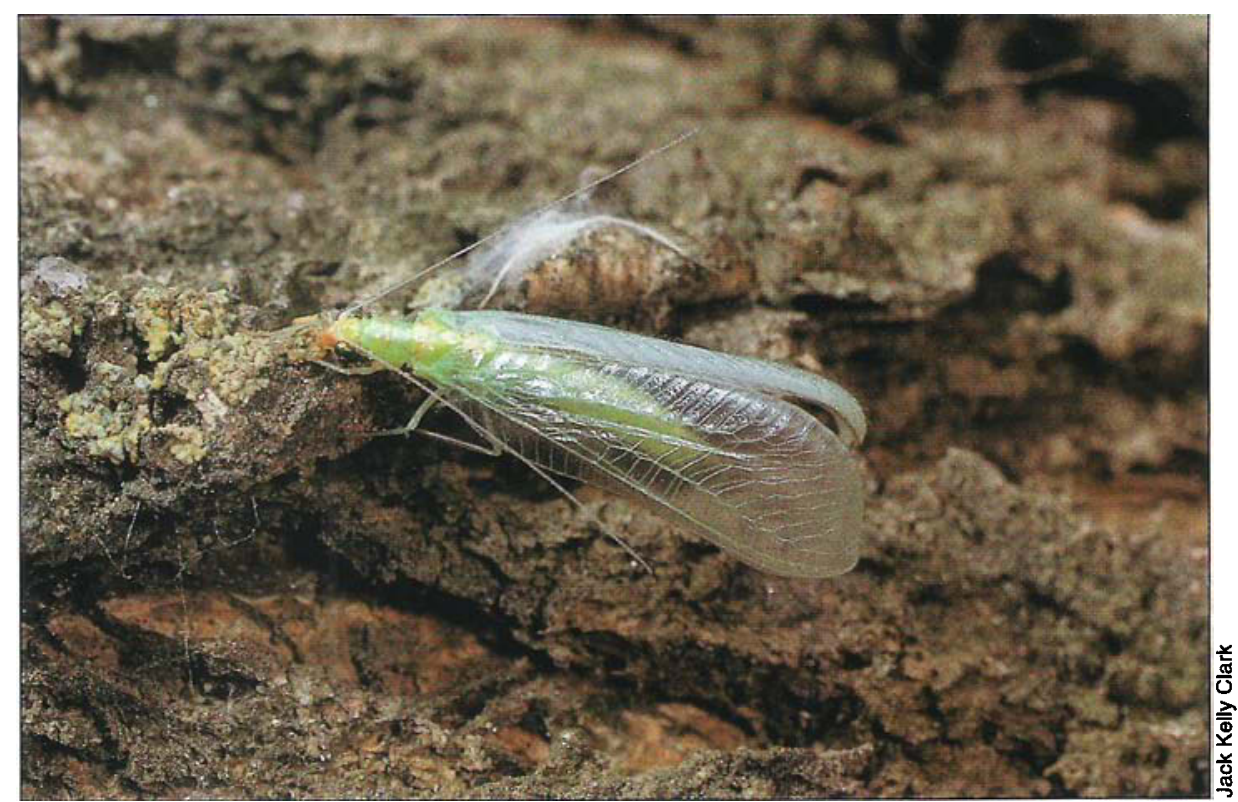

Natural lacewing populations are important because each adult can lay over 1,000 eggs.

\title{
Effectiveness of leafhopper control varies with lacewing release methods
}

\author{
Kent M. Daane $\square$ Glenn Y. Yokota $\square$ Yvonne D. Rasmussen $\square \quad$ Yuwei Zheng \\ Kenneth S. Hagen
}

The variegated grape leafhopper, Erythroneura variabilis, has been the primary insect pest in San Joaquin Valley grape vineyards for the past decade. Leafhopper nymphs and adults damage the leaves by feeding, which reduces photosynthesis, and the fruit by excreting honeydew, which leads to sooty mold growth. Also, the flying adults are a nuisance to workers at harvest and reduce their productivity. To control leafhoppers, most grape growers rely on pesticide treatments; however, these treatments can disrupt the natural control of spider mites and mealybugs, and there has been some leafhopper resistance to commonly used insecticides.

To improve natural control, some grape growers are using augmentative releases of green lacewings, Chrysoperla species, and have reported a reduction or complete elimination of pesticide applications for leafhoppers. Our laboratory studies show that lacewings are indeed voracious predators of the variegated leafhopper, with each larva consuming an average of 252.4 large leafhopper nymphs during its 10-day development period. The potential seems encouraging; however, large-scale lacewing release programs for controlling leafhoppers have produced mixed results. Growers need better guidelines for these programs than are currently available.

In our experiments, we examined the effectiveness of lacewing releases in grape vineyards and, based upon the field data, we can now suggest improvements to commercial programs.

\section{Experimental plot trials}

To determine the field effectiveness of lacewings as leafhopper predators, a series of small-plot experiments were conducted with varying release rates and schedules. In all trials, first instar lacewing larvae were placed on leaves with a camel-hair brush. Previous work had shown that releases of larvae, rather than eggs, provided greater control of the release number due to the variability in egg hatch and survivorship. Leafhopper densities were determined every 2

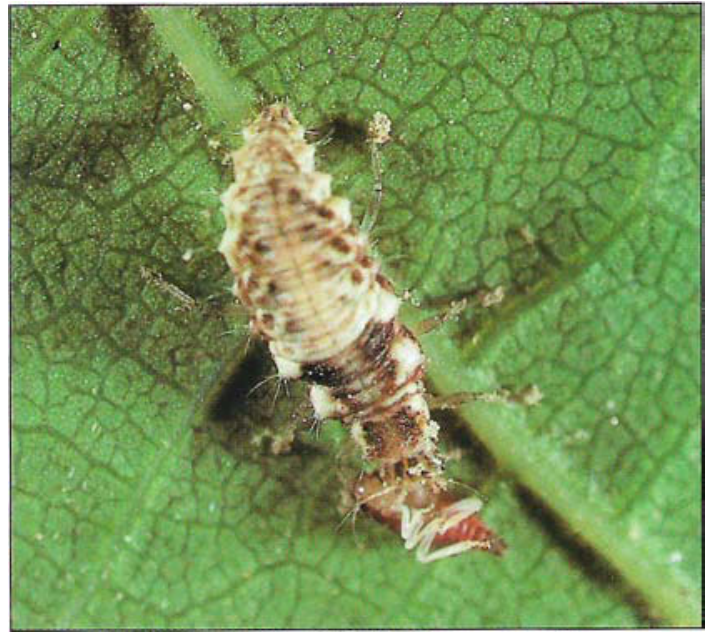

Chrysoperla comanche feeding on a fifth instar variegated leafhopper. 


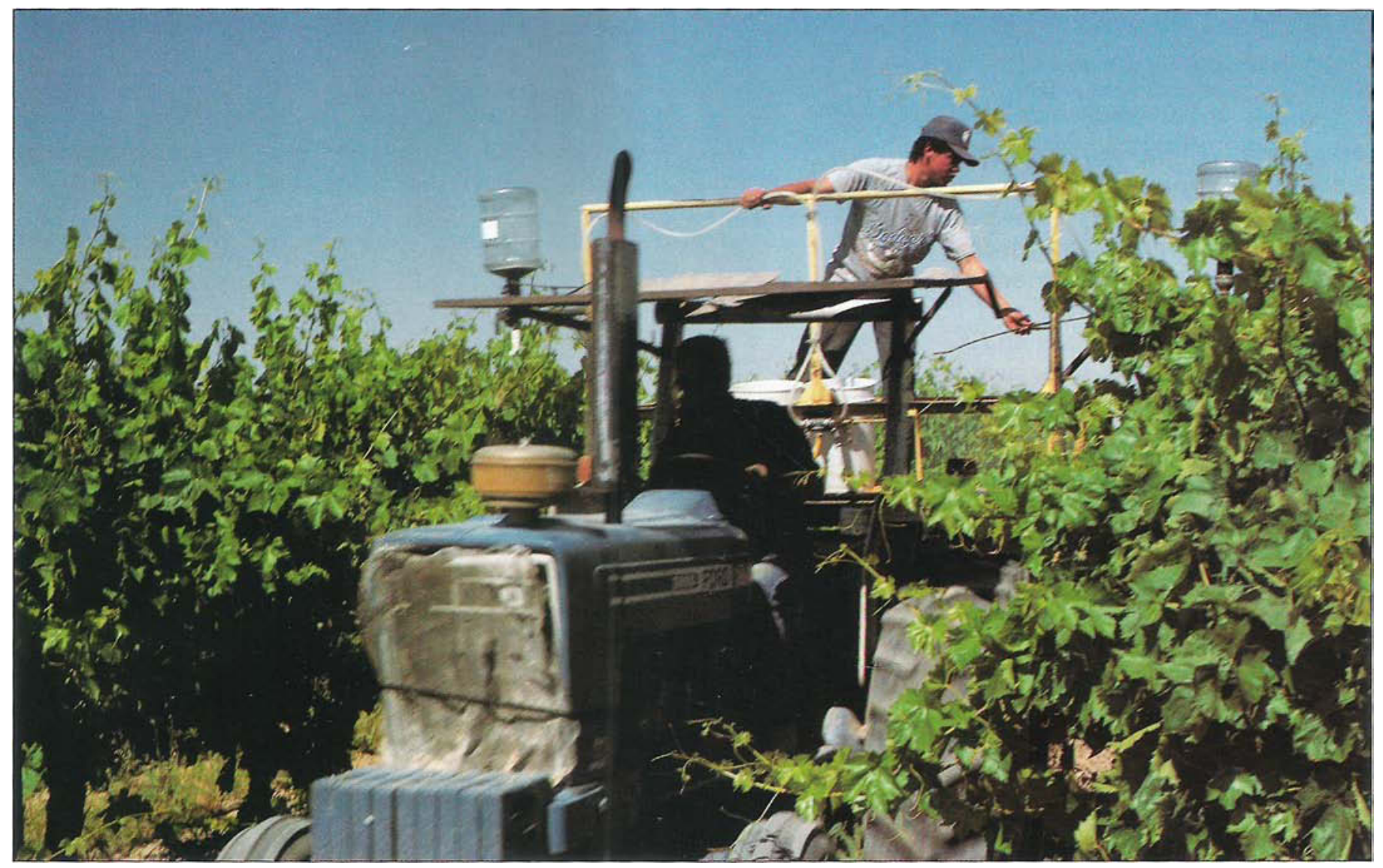

Lacewing eggs were mixed with corn grit and placed in 5-gallon containers. By adjusting the funnel size at the bottom of the container, the release rate could be controlled.

weeks from nymphal counts on $10(1990$ and 1991) and 20 (1992) leaves per plot. For each release treatment, the equivalent number of lacewings per acre is given in table 1.

In 1990, lacewings were released into cages that enclosed one-quarter of a vine. The cages were set in a randomized block design, with three treatments: 1) no release, 2) 6 lacewings per cage and 18 lacewings per cage. Releases were made according to a "calendardate" schedule. Most growers release lacewings at peak leafhopper density, estimating that period to be near June 1 and July 15 for the first and second leafhopper broods, respectively, in the San Joaquin Valley. We made our releases accordingly, with slight adjustments to match lacewing delivery and vineyard management practices.

The study was repeated in 1991 and 1992 in three-vine plots. Each plot was isolated by pruning border vines throughout the season and covering the exposed wire trellis with a barrier of Tanglefoot, which effectively prevented lacewing larvae and leafhopper nymphs from moving among plots.
In 1991, four treatments were set up: 1) no release; 2) 24 lacewings per plot, with release timed by calendar date; 3 ) 24 lacewings per plot, with a "synchronized" release - timed at 50\% to $70 \%$ leafhopper egg hatch to match the released lacewings with the small leafhoppers - and 4) 48 lacewings per plot, with a synchronized release.

In 1992, we set up two treatments in the first leafhopper brood: 1) no release and 2) 48 lacewings per plot, with a calendar-date release. In the second brood, we tested possible differences among lacewing species, in four treatments: 1) no release, 2) 48 C. carnea per plot, 3) 48 C. comanche per plot and 4) $48 \mathrm{C}$. rufilabris per plot, each with a synchronized release.

\section{Commercial vineyard trials}

To test the effectiveness of lacewings in commercial release programs, 150 vine plots were established in three Thompson seedless vineyards. The vineyards were mature ( $>10$ years) and had similar cultural practices (pruned for raisins, no cover crops, furrow irrigation, and standard application of fertilizer).
Treatments were established in a randomized block design.

In 1991, two treatments were set up: 1) no release and 2) a machine release of lacewing eggs mixed with corn grit. In 1992, a hand release of lacewing larvae, at the same rate as the machine release of lacewing eggs, was added as a third treatment. In both years, lacewings were released at approximately 3,500 per acre, in one and two releases in the first and second leafhopper broods, respectively, totaling approximately $10,500 \mathrm{C}$. carnea per acre. Releases were made on a calendar-date schedule. Leafhopper densities were monitored with biweekly nymphal counts on 20 leaves from the center 30 vines in each plot.

\section{Release method trials}

In vineyards, the most common lacewing release method is to mix lacewing eggs with a medium, such as corn grit, vermiculite or rice hulls, and then spread the mixture over the vines. In the vineyards monitored, lacewing eggs were combined with corn grit, and the mixture was placed in 5-gallon containers, which were mounted on a platform 
above the vines. The containers had an adjustable funnel opening at the bottom; by changing either the funnel opening or the tractor speed, the release rate could be controlled. A series of tests were conducted to determine the number and viability of eggs delivered and the resulting number of lacewing larvae in the field.

The number of lacewing eggs delivered to each vine was measured by collecting $0.75-\mathrm{oz}(25-\mathrm{ml})$ samples of the egg/corn-grit mixture at the beginning and toward the end of one 2-gallon (7.6liter) release batch. The number of vines covered by each sample was recorded. The samples were dissected in the laboratory, and the number of live, hatched, crushed (from the mixing process) and dead (from the insectary mix) eggs and live or dead larvae were recorded.

After delivery to the vines, egg mortality (before egg hatch) can be affected by high temperatures, placement on or off the vine and predators (see California Agriculture, September-October 1993). Presumably, these mortality factors have a greater effect the longer the egg is in the field before egg hatch. To test the mortality of fresh eggs and compare egg and larval releases, three-leaf plots were used, set in a randomized block design, with three treatments: 1) no release, 2) three fresh $C$. comanche eggs per plot and 3 ) three $C$. comanche first instar larvae per plot. Leafhopper and lacewing densities were determined every 2 or 3 days, until no lacewing larvae were found.

To determine lacewing larvae recovery in the field, we sampled 3,000 to 6,000 leaves in each commercial vineyard monitored in 1991-92, 5 to 10 days after the lacewing release dates. The number of live or hatched eggs (on stalks) and lacewing larvae were recorded.

\section{Experimental plot results}

Results in the experimental plots for each year generally show lower leafhopper densities in lacewing release plots than in the control plots (table 1). In the 1990 cage trial, the difference between the release and control plots was greatest at the release rate of 36,000 eggs per acre, which resulted in a significant 42 and $29.4 \%$ reduction in leafhopper numbers in the second and third broods, respectively $(\mathrm{P}<0.05)$. However, at current costs for lacewing eggs, about $\$ 3$ per 1,000 , that release rate may be economically prohibitive (about $\$ 108$ per acre) for the level of control achieved. Also, the cages prevented the lacewing larvae from moving off the vine and predators of the lacewings from moving
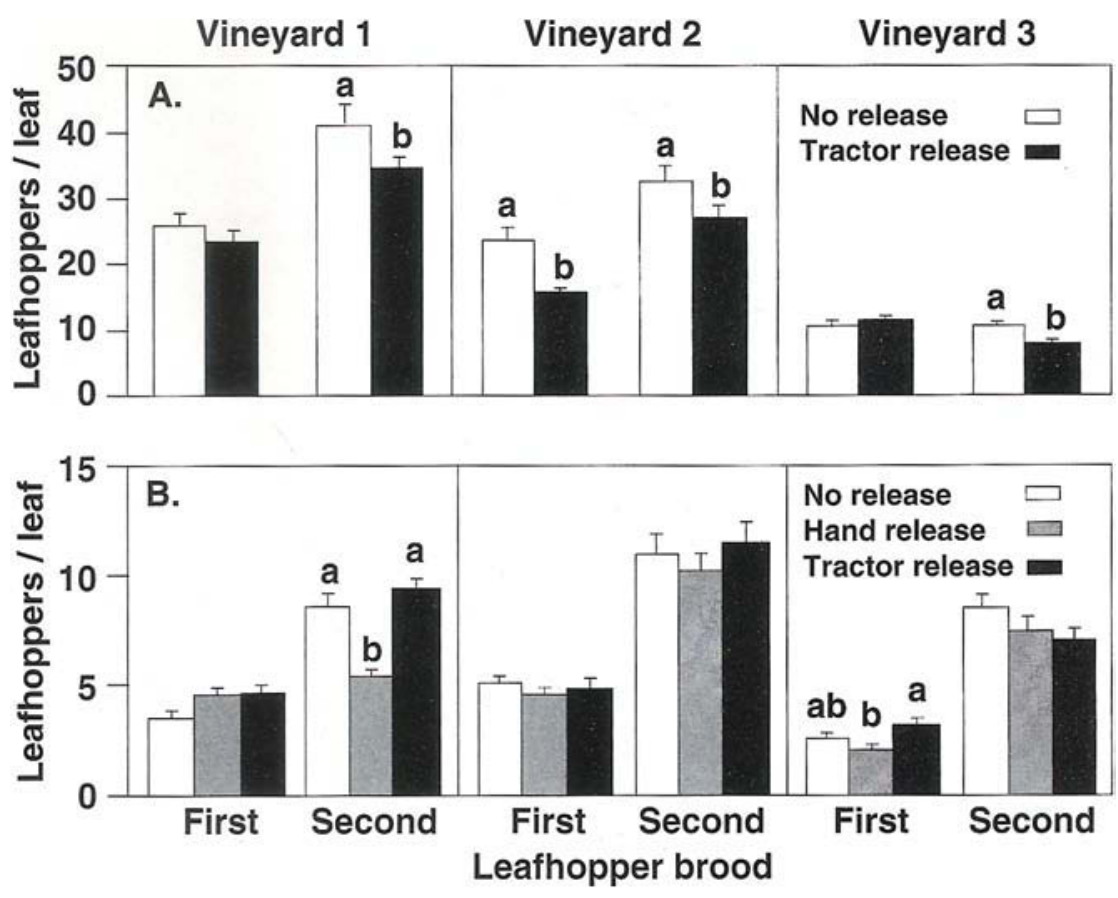

Fig. 1. Average leafhopper densities found in lacewing release and no release plots in three Thompson seedless vineyards in (A) 1991 and $(B)$ 1992. C. carnea eggs were released at approximately 3,500/acre in the first brood and 7,000/acre in the second brood. Mean leafhopper densities, in each brood and vineyard, topped with different letters are significantly different $(P<0.05)$.

TABLE 1. Leafhopper (LH) density pre- and post-lacewing (LW) releases in quarter-vine cage (1990) and three-vine (1991-92) plots

\begin{tabular}{|c|c|c|c|c|c|c|}
\hline \multirow{4}{*}{$\frac{\text { Year }}{1990}$} & \multirow{2}{*}{$\begin{array}{c}\begin{array}{c}\text { LH } \\
\text { brood }\end{array} \\
\text { 2nd }\end{array}$} & \multirow[t]{2}{*}{$\begin{array}{c}\text { LW } \\
\text { species }\end{array}$} & \multirow[t]{2}{*}{$\begin{array}{c}\text { Release } \\
\text { schedule }^{\star}\end{array}$} & \multirow{2}{*}{$\begin{array}{r}\begin{array}{c}\text { LW } \\
\text { release } \\
\text { ratet }\end{array} \\
0\end{array}$} & \multicolumn{2}{|c|}{$\begin{array}{l}\text { Post- } \\
\text { release } \\
\text { LH/Leaf } \neq\end{array}$} \\
\hline & & & & & 10.7 & $\pm 1.1 \mathrm{a}$ \\
\hline & & C. carnea & calendar & 12,000 & 8.1 & $\pm 1.0 \mathrm{ab}$ \\
\hline & & C. carnea & calendar & 36,000 & 6.2 & $\pm 0.9 b$ \\
\hline & 3rd & ................... $\mathrm{CC}$ & ………… & & 30.6 & $\pm 2.9 \mathrm{a}$ \\
\hline & & C. carnea & calendar & 12,000 & 23.6 & $\pm 1.8 b$ \\
\hline & & C. carnea & calendar & 36,000 & 21.8 & $\pm 1.3 b$ \\
\hline \multirow[t]{8}{*}{1991} & $1 \mathrm{st}$ & 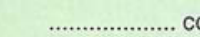 & ................. & 0 & 12.5 & $\pm 1.7 \mathrm{ab}$ \\
\hline & & C. carnea & calendar & 4,000 & 8.6 & $\pm 1.4 \mathrm{bc}$ \\
\hline & & C. carnea & synchronized & 4,000 & 14.5 & $\pm 1.4 \mathrm{a}$ \\
\hline & & C. carnea & synchronized & 8,000 & 8.3 & $\pm 1.0 \mathrm{c}$ \\
\hline & 2nd & 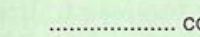 & 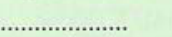 & 0 & 17.8 & $\pm 2.2 \mathrm{a}$ \\
\hline & & C. carnea & calendar & 4,000 & 20.1 & $\pm 2.2 \mathrm{a}$ \\
\hline & & C. carnea & synchronized & 4,000 & 15.5 & $\pm 2.3 \mathrm{ab}$ \\
\hline & & C. carnea & synchronized & 8,000 & 12.2 & $\pm 1.3 b$ \\
\hline \multirow[t]{7}{*}{1992} & $1 \mathrm{st}$ & .................. $\mathrm{CC}$ & ...................... & 0 & 2.3 & $\pm 0.2 \mathrm{a}$ \\
\hline & & C. carneal & & & & \\
\hline & & C. comanche ** & calendar & 8,000 & 2.4 & $\pm 0.2 \mathrm{a}$ \\
\hline & 2nd & $\ldots \ldots \ldots \ldots \ldots \ldots \ldots$ & ....................... & 0 & 1.3 & $\pm 0.1 \mathrm{a}$ \\
\hline & & C. carnea & synchronized & 8,000 & 2.0 & $\pm 0.1 \mathrm{~b}$ \\
\hline & & C. comanche & synchronized & 8,000 & 1.5 & $\pm 0.1 \mathrm{a}$ \\
\hline & & C. rufilabris & synchronized & 8,000 & 0.9 & $\pm 0.1 \mathrm{c}$ \\
\hline
\end{tabular}

*Calendar-date releases were made near June 1 (first LH brood) and July 15 (second LH brood). Synchronize releases were made at 50 to $70 \%$ LH egg hatch, as monitored by leaf counts.

tLW were released at 6 or 18 per cage (1990) or 24 or 48 per plot (1991-92) on one or two release dates in each $\mathrm{LH}$ brood. Comparable field release rates given are based on 500 vines per acre.

$\neq$ Post-release LH densities (xo) were normalized $(x n)$ to account for slight differences in pre-release LH densities $(y)$ between treatments $(t)[x n=x 0+(\mu t-\mu y)]$. Statistical analyses were made on the percentage change in LH numbers in each treatment from pre- to post-LW-release dates. For each year and LH brood, means followed by different letters, in each group, are significantly different (ANOVA, Tukey pairwise comparison $\mathrm{P}<0.05$ )

**The insectary mix was approximately $85 \%$ C. carnea and $15 \%$ C. comanche. 


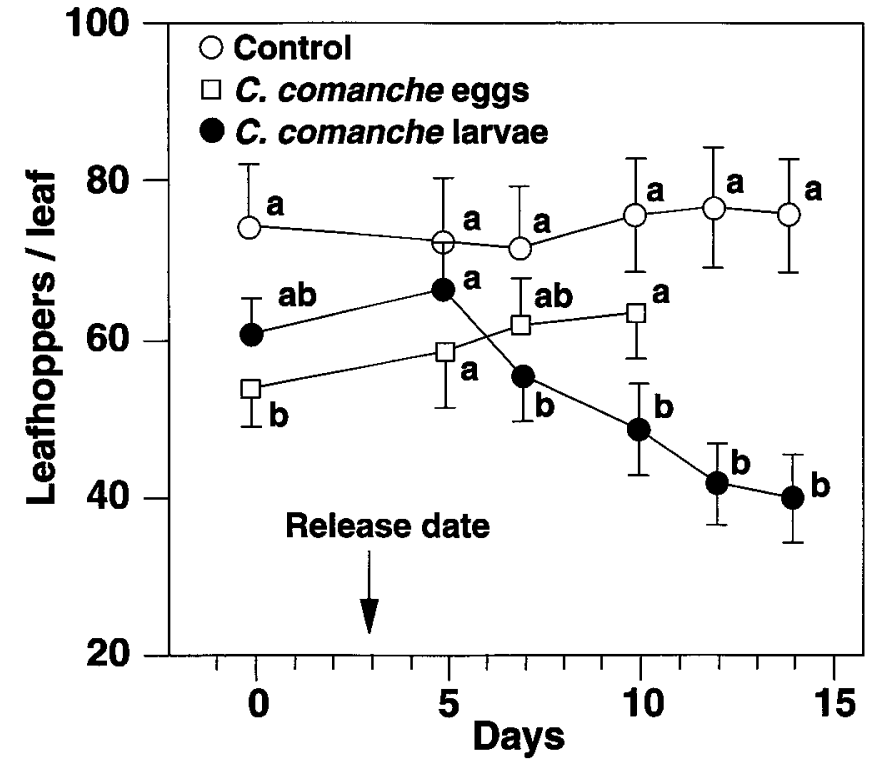

Fig. 2. The average leafhopper density in three-leaf plots that received first instar $C$. comanche larvae was significantly lower than in the control plots or in the plots that received fresh $C$. comanche eggs $(P<$ 0.05 ). Field hatch of freshly laid eggs was less than $20 \%$ in this study. Mean leafhopper densities, on each sample date, topped with different letters, are significantly different $(P<0.05)$. onto the vine, which most certainly affected the results.

In 1991, we changed the release rates to more closely reflect commercial rates, typically around 3,000 to 4,000 lacewings per acre at each release, with one or two releases in the first and again in the second leafhopper broods. At the higher release rate of 8,000 lacewings per acre, a significant $33.6 \%$ and $31.4 \%$ reduction in leafhopper density were found in the first and second brood, respectively $(P<$ $0.05)$. Results were less consistent at the lower release rate of 4,000 lacewings per acre, tested on both release schedules. In the calendar-date release, a $31.2 \%$ decrease and a $12.9 \%$ increase in leafhopper density were recorded in the first and second leafhopper broods, respectively. In the synchronized release plots, there was a $16 \%$ increase and a $12.9 \%$ decrease, respectively.

In 1992, there was no significant between-treatment differences in the first brood leafhopper densities. In the second brood, comparing releases of $C$. carnea, $C$. comanche and $C$. rufilabris, only C. rufilabris significantly reduced leafhopper density compared with the control plots $(P<0.05)$. Leafhopper density, at the time of the release, was fewer than 5 per leaf, far below any suggested economic injury level, which reduces the importance of this trial as a comparison of lacewing species. However, comparing data from the other trials over the three years, it was clear that with similar release rates there was a lower-per-leaf leafhopper mortality when leafhopper densities were low than when they were high.

\section{Commercial vineyard results}

Results in 1991 show a trend of lower leafhopper numbers in lacewing release plots than in no release plots (fig. 1a). In the first brood, there was a significant $(P$ $<0.05$ ) reduction in leafhoppers in only one vineyard; however, in that vineyard the $34.9 \%$ decrease, from 23.2 to 15.1 leafhoppers per leaf, brought the average leafhopper density down to the suggested economic injury threshold of 15 leafhoppers per leaf (Grape Pest Management, DANR publication No. 3343).

In the second brood, there was a significant reduction in leafhoppers in each vineyard (fig. 1a). But although significant, the reduced leafhopper densities in vineyards 1 and 2 remained above the suggested economic injury threshold. Thus, at leafhopper densities above 30 per leaf, the release rates used appeared to be too low to bring about the necessary (more than $50 \%$ ) decrease in leafhopper numbers. In vineyard 3, leafhopper density was below the suggested economic injury threshold in both the release and control plots, and the average reduction in release plots amounted to only 2.4 leafhoppers per leaf.

In 1992, leafhopper densities were low (fig. 1b), never exceeding the suggested economic injury threshold. In only one of the three vineyards, vineyard 1 , was a significant reduction in leafhopper densities recorded, a $36.7 \%$ reduction of leafhopper numbers in the hand release treatment compared with the control plots $(P<0.05)$. The actual decrease was 3 leafhoppers per leaf. As in the experimental plots, the effectiveness of lacewing releases is apparently correlated to the leafhopper density at the time of release. At low leafhopper densities, lacewings consume less, because of the time spent searching for sparse prey, among other factors.

\section{Release method results}

Results from the egg delivery test showed that $4.0, \pm 0.5, \mathrm{ml}$ of the corn grit and egg mixture was delivered to each vine. The average number of eggs in each 25 -ml sample was $39.5, \pm 6.2$, making egg delivery approximately 6.3 lacewings per vine, or 3,160 per acre in each release. This number corresponded well to the growers' desired release level of 3,000-4,000 lacewings per acre. However, delivery of eggs throughout the vineyard was uneven. The average number of lacewing eggs per 25-ml sample taken at the beginning of one release batch $(55.3, \pm 8.6)$ was significantly greater than the number collected at the end $(23.9, \pm 3.9)(P=0.003)$. The results implied that as the tractor moved the eggs sifted to the bottom of the release container and were delivered in greater numbers to the beginning rows. There was also a great range (min. 5, max. 119) in the number of eggs per sample, which indicated an uneven distribution of eggs in the field.

Results from the studies testing the viability of delivered eggs showed that the method of egg dispersal caused some egg mortality, which can be expected with almost any delivery system. After dissecting the mixture, we found $62 \%$ survivorship of the eggs delivered to the vines (live eggs plus larvae), $35.5 \%$ crushed eggs (from the mixing process) and $2.5 \%$ dead eggs. The low number of dead eggs is typical for the material received from insectaries, with most mortality occurring after shipment, during storage and delivery. The percentage of live eggs delivered to the vines was acceptable when compared with other delivery methods. For example, air delivery of eggs to vines places much of the material on the ground, where it will remain. The corn grit may cause some mortality by increasing egg desiccation. Other mixing substances, such as vermiculite, have been reported to result in less egg mortality, but were difficult to use with the cooperating growers' systems. Of course, different release methods may be more suited to other crops.

The egg and larvae release experiment, with $C$. comanche in three-leaf plots, tested field egg hatch of fresh insectary eggs. Results showed that egg hatch took over 4 days, with less than $20 \%$ egg hatch. The effect of egg compared with larval release on leafhopper 
densities was evident. There was no difference between leafhopper numbers in egg release and control plots. In plots receiving larvae, leafhopper numbers were significantly $(P<0.001)$ lower than those in the control (fig. 2).

From this work and field observations, we agree with the many insectary managers who suggest that it is best to release lacewings when eggs are ready to hatch or already have begun. For vineyards, we suggest a $25 \%$ to $50 \%$ egg hatch at the release date. While there will be some cannibalism, the viability of the material delivered to the vines will be increased.

Results of the larvae recovery test showed no significant difference $(\mathrm{P}>$ 0.05 ) between release and control plots; both had fewer than 1 larva per 1,000 leaves sampled. This poor recovery figure does not necessarily mean that there were low lacewing densities in the field; it reflects the difficulty of sampling for lacewing larvae, given their mobility and the low release rate compared to the number of leaves on the vine. Evidence of high natural lacewing populations was obvious from the number of eggs laid on stalks in both the release and control plots. The highest densities of lacewing eggs recorded ( 15 eggs per 100 leaves) were in vineyards adjacent to peach or almond orchards, which had not received any commercial lacewings. However, the low number of larvae found in these vines again raises the question of the importance of the natural enemies of the lacewing (see California Agriculture, September-October 1993).

\section{Conclusions}

Green lacewings are one of the most common commercially reared natural predators. Our studies in experimental plots and commercial vineyards showed that releases of green lacewings at rates between 3,000 and 8,000 per acre for each leafhopper brood (costing $\$ 9$ to $\$ 24$ per acre for each brood) reduced leafhopper densities up to $35 \%$. However, there was a great variability in release effectiveness, with leafhopper densities in some release plots showing no difference compared to controls.

The method of releasing the lacewings was an important factor in their effectiveness. Egg delivery to the vines was uneven throughout the vineyard, and there was up to $38 \%$ egg mortality (in delivered eggs). Proper release timing was also important, with releases synchronized to leafhopper egg hatch resulting in a greater reduction of leafhoppers than releases based on calendar dates. Unfortunately, synchronized releases are more difficult because lace-

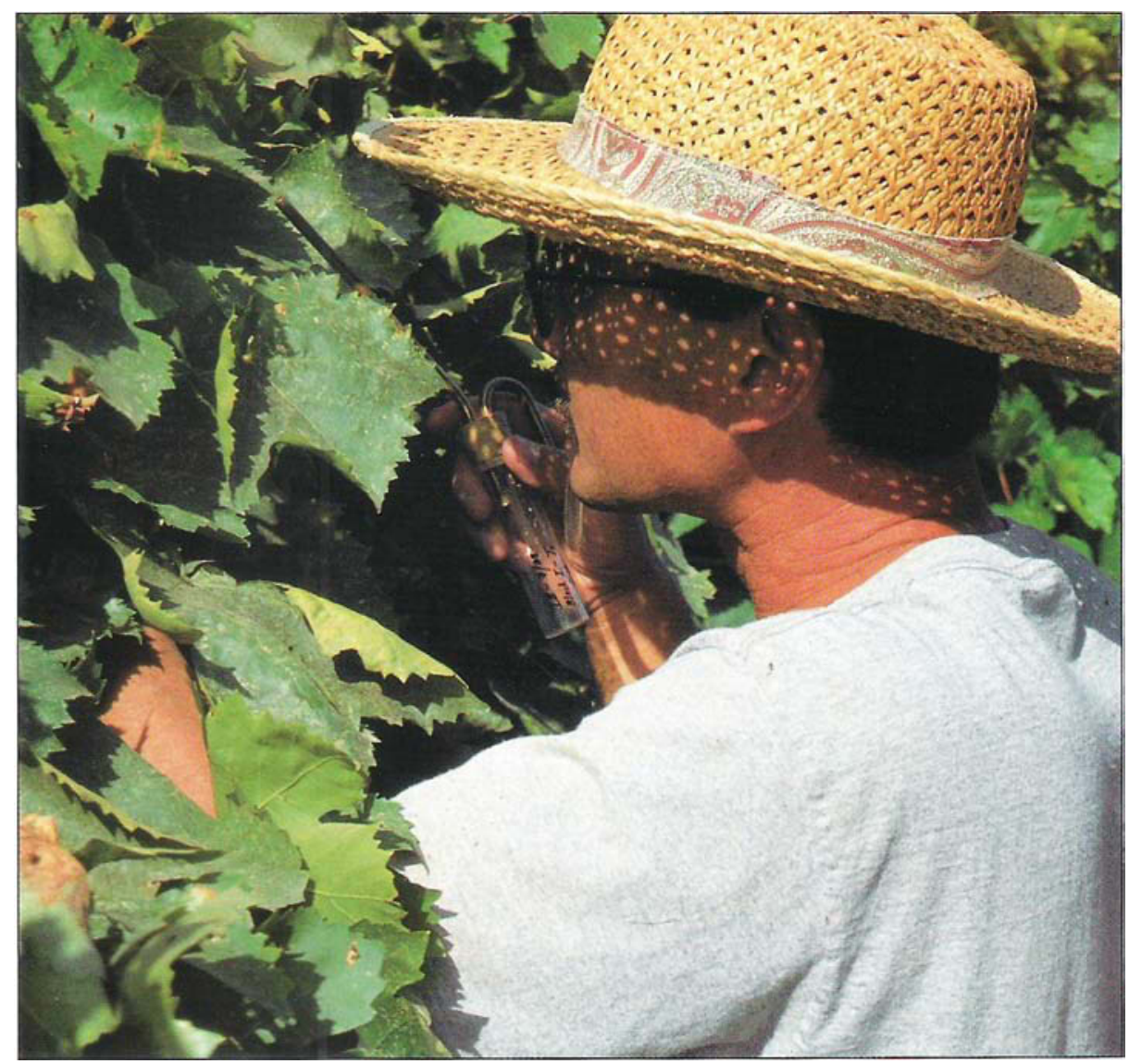

Staff Research Associate Glenn Yokota monitors for leafhopper nymphs and lacewing eggs and larvae in a commercial vineyard trial.

wings must be ordered in advance to ensure timely delivery and then, after the lacewings have been shipped to the grower, the release has to be scheduled around other management practices, such as irrigation.

Our studies suggested how the level of leafhopper control with augmentative lacewing releases could be improved. First, leafhopper densities should be carefully monitored so lacewing releases can be matched to the beginning of each leafhopper brood. This will pair the newly hatched lacewings with the smaller stage leafhoppers. Monitoring the leafhopper density in each block will also provide the grower with a better determination of which blocks are appropriate for lacewing releases. Our results suggested that leafhopper densities between 15 and 25 per leaf can be reduced to below the suggested economic injury threshold (15 per leaf) with lacewing releases. However, leafhopper densities greater than 30 per leaf cannot be reduced below the threshold at release rates economically comparable to insecticidal treatments. Similarly, at low leafhopper densities (fewer than 5 per leaf) the decrease in leafhopper numbers is not economically efficient.

Finally, the most important part of the release program is the careful deliv- ery of the eggs. Improved methods are currently being developed by university and insectary personnel. Until a method has been perfected, to reduce egg mortality, we suggest applying a rate based on a $25 \%$ to $50 \%$ egg hatch at the release date. Insectaries also stress the importance of proper storage before delivery and will work with their customers to deliver viable material at the proper time.

K. M. Daane is Associate Specialist, G. Y. Yokota is Staff Research Associate, Y.D. Rasmussen was Laboratory Assistant, $Y$. Zheng was Postdoctoral Research Associate, and K. S. Hagen is Professor Emeritus, Laboratory of Biological Control.

Funding for this research was provided by the California Table Grape Commission, the California Raisin Advisory Board and the UC Statewide IPM Project.

The authors thank Bill Barnett, Areawide IPM Specialist; Jake Blehm, Buena

Biosystems Insectary; Everett Dietrick, Rincon-Vitova Insectaries; Hunter Nadler; Sinthya Penn, Beneficial Insectary; and Rob Roy, Gallo Vineyards, for helpful suggestions throughout the project; and the Hansen, KAC, Nadler, Rocca, Radoicich, Smeds, Swansen and Yokota farms for use of their vineyards in some of the experiments. 